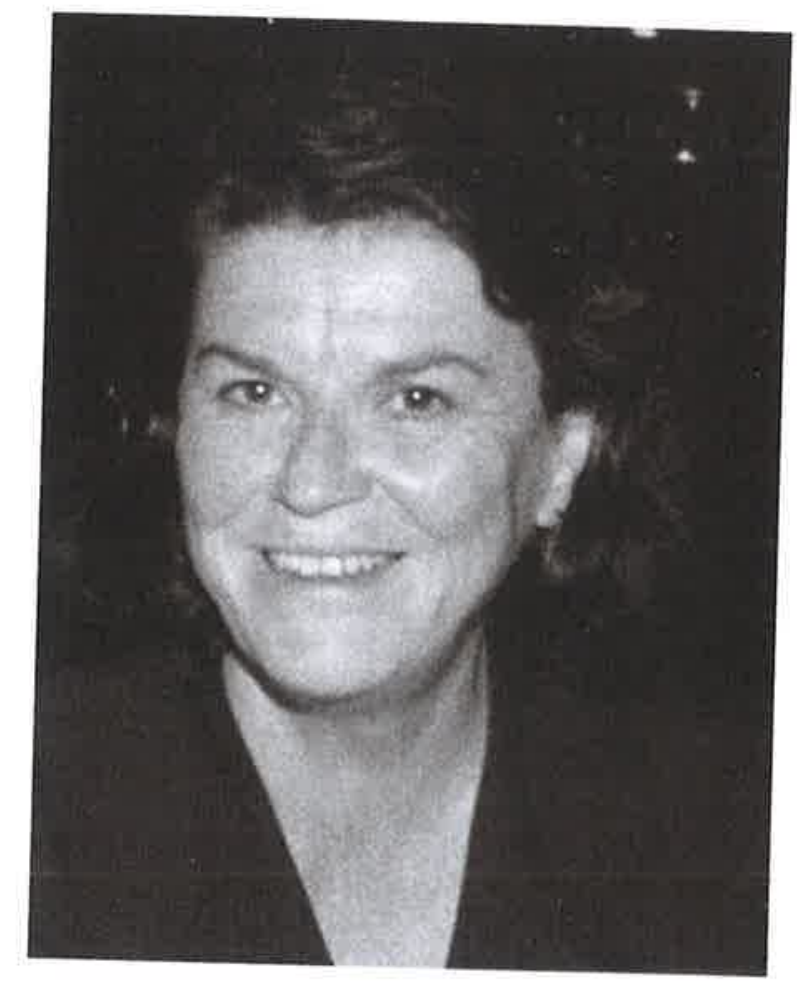

Jorge Vala - Sven Waldzus

Maria Manuela Calheiros

Editors

\title{
The Social Developmental Construction of Violence and Intergroup Conflict
}

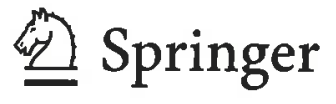


Editors

Jorge Vala

Instituto de Ciências Sociais (ICS-UL)

Universidade de Lisboa

Lisbon

Portugal

Maria Manuela Calheiros

CIS-IUL

Instituto Universitário de Lisboa (ISCTE)

Lisbon

Portugal

\section{Sven Waldzus}

CIS-IUL

Instituto Universitário de Lisboa (ISCTE)

Lisbon

Portugal

ISBN 978-3-319-42726-3

ISBN 978-3-319-42727-0 (eBook)

DOI $10.1007 / 978-3-319-42727-0$

Library of Congress Control Number: 2016944915

(C) Springer International Publishing Switzerland 2016

This work is subject to copyright. All rights are reserved by the Publisher, whether the whole or par of the material is concerned, specifically the rights of translation, reprinting, reuse of illustrations, recitar, broadcasting, reproduction on microfilms or in any other physical way, and transmission methodology now known or hereafter devolc adaptation, computer software, or by similar or dissimilar The use of gew known or hereatter developed.

The use of general descriptive names, registered names, trademarks, service marks, etc. in this pabication does not imply, even in the absence of a specific statement, that such names are exempt from the relevant protective laws and regulations and therefore free for general use.

The publisher, the authors and the editors are safe to assume that the advice and information in this book are believed to be true and accurate at the date of publication. Neither the publisher nor the for for any errors or omissions that may have been made.

Printed on acid-free paper

This Springer imprint is published by Springer Nature

The registered company is Springer International Publishing AG Switzerland 


\section{Contents}

Part I Power, Self and Intergroup Relations

1 Power and the Social Self. Ana Guinote and Alice Cai

2 From a Sense of Self to Understanding Relations Between Social Groups $\ldots \ldots \ldots \ldots \ldots \ldots \ldots \ldots \ldots \ldots \ldots \ldots$ Dalila Xavier de França

3 Intergroup Relations and Strategies of Minorities Joana Alexandre, Miriam Rosa and Sven Waldzus

Part II Social Construction of Identities and Social Categories

4 "Back to the Future:" Ideological Dimensions of Intergroup Relations . Jacques-Philippe Leyens and Jorge Vala

5 The Common Ingroup Identity Model and the Development of a Functional Perspective: A Cross-National Collaboration

Sam Gaertner, Rita Guerra, Margarida Rebelo, John Dovidio,

Erick Hehman and Mathew Deegan

6 When Beliefs Become Stronger than Norms: Paradoxical Expressions of Intergroup Prejudice Annelyse Pereira

\section{Part III Social Developmental Processes of Violence}

7 Parent-Child Interactions as a Source of Parent Cognition in the Context of Child Maltreatment

Maria Manuela Calheiros and Leonor Rodrigues 
8 The Promotion of Violence by the Mainstream Media

of Communication . . . . . . . . . . . . . . . . . . . . 171

Patrícia Arriaga, Dolf Zillmann and Francisco Esteves

9 Creating a More Inclusive Society: Social-Developmental Research on Intergroup Relations in Childhood and Adolescence . . . . . . . . . . . . . . . . . . . . . . . . . . . . . 197

João H. C. António, Rita Correia, Allard R. Feddes and Rita Morais

10 The Multi-Norm Structural Social-Developmental Model of Children's Intergroup Attitudes: Integrating

Intergroup-Loyalty and Outgroup Fairness Norms .

Ricardo Borges Rodrigues, Adam Rutland and Elizabeth Collins

\section{Contributors}

Joana Alexandre CIS-IUL, Instituto Universitário de Lisboa (ISCTE-IUL), Lisbon, Portugal

João H.C. António CIS-IUL, Instituto Universitário de Lisboa (ISCTE-IUL), Lisbon, Portugal

Patricia Arriaga CIS-IUL, Instituto Universitário de Lisboa (ISCTE-IUL), Lisbon, Portugal

Alice Cai University College of London, London, UK

Maria Manuela Calheiros CIS-IUL, Instituto Universitário de Lisboa (ISCTE-IUL), Lisbon, Portugal

Elizabeth Collins CIS-IUL, Instituto Universitário de Lisboa (ISCTE-IUL), Lisbon, Portugal

Rita Correia CIS-IUL, Instituto Universitário de Lisboa (ISCTE-IUL), Lisbon, Portugal

Mathew Deegan University of Delaware, Newark, DE, USA

Dalila Xavier de França Sergipe Federal University-UFS, Aracaju, Brazil

John Dovidio Yale University, New Haven, CT, USA

Francisco Esteves CIS-IUL, Instituto Universitário de Lisboa (ISCTE-IUL), Lisbon, Portugal; Mid Sweden University, Härnösand, Sweden

Allard R. Feddes University of Amsterdam, Amsterdam, The Netherlands

Sam Gaertner University of Delaware, Newark, DE, USA

Rita Guerra CIS-IUL, Instituto Universitário de Lisboa (ISCTE-IUL), Lisbon, Portugal 
Ana Guinote University College of London, London, UK; Leardership Knowledge Center, Nova School of Business and Economics, Lisbon, Portugal

Erick Hehman Dartmouth College, Hanover, NH, USA

Jacques-Philippe Leyens Catholic University of Louvain-La-Neuve, Louvain-LaNeuve, Belgium

Rita Morais CIS-IUL, Instituto Universitário de Lisboa (ISCTE-IUL), Lisbon, Portugal

Annelyse Pereira CIS-IUL, Instituto Universitário de Lisboa (ISCTE-IUL), Lisbon, Portugal

Margarida Rebelo National Laboratory of Civil Engineering (LNEC), Lisbon, Portugal

Leonor Rodrigues Institute of Social Sciences (ICS-ULisboa), Universidade of Lisbon, Lisbon, Portugal

Ricardo Borges Rodrigues CIS-IUL, Instituto Universitário de Lisboa (ISCTE-IUL), Lisbon, Portugal

Miriam Rosa CIS-IUL, Instituto Universitário de Lisboa (ISCTE-IUL), Lisbon, Portugal

Adam Rutland Goldsmiths, University of London, London, UK

Jorge Vala Instituto de Ciências Sociais (ICS-ULisboa), Universidade de Lisboa, Lisbon, Portugal

Sven Waldzus CIS-IUL, Instituto Universitário de Lisboa (ISCTE-IUL), Lisbon, Portugal

Dolf Zillmann University of Alabama, Tuscaloosa, USA

\section{Introduction and Overview}

At the moment we write this introduction, Europe faces a dramatic situation: Hundreds of thousands of war refugees are knocking on Europe's doors asking for shelter. These people think that here is a place of freedom, peace and laws that guarantee their human dignity, without exception. Europe for itself is alert, seems undecided, if not divided. Heads of state haggle over refugee quotas with their EU colleagues, while some communities and cities try their best to solve the logistic challenges popping up everywhere, many signaling upwards that they are on their limits. Whereas citizens in all affected countries spontaneously provide food and support as volunteers, borders are closed in panic in some countries; quite unsuspicious middle-class people join crowds manifesting their unwillingness to accep picion refugees and enemies of the open society seem to feel that their hour has more refugees and Politics is shaking, the right for asylum, fundamental part of European constitution, seems out of a sudden legis can be granted or not, a political option that negotiable, turning into a mercy that can be gres decide to define themselves as a national group that is generous or tough.

Is it possible that such situations occur without provoking an even stronger,

Is it possible thation of humans for the defense of other humans? It Mental walls divide us and the people (demos) that used to be one whole and exclude now as ethnos those others whose essence places them outside the scope of where the principles of justice apply.

Which mental processes feed these situations? This book opens ways of understanding such phenomena and proposes ways of action. These ways open up in such a fertile research area as social psychology is indeed. They part from the supposition that there is no discrimination, benign or blatant, no collective crime and no institutionalized violence that does not involve social relations between groups.

However, this book raises some questions that go beyond the more traditional research on the social psychology of intergroup relations. First, while dedicating an 
important part of investigation to the description and explanation of intergroup discrimination, social psychology has often overlooked that discrimination is not a question of mere ingroup favoritism but a phenomenon that manifests itself in social inequality, violence and aggression, often hidden, legislated or legitimized.

We would say that the very term discrimination, filling social psychology books on intergroup relations, reveals some hesitation in the naming of what often is not just a question of quantity (some more for my group than for yours), but a question of inequality that involves violence and aggression. This book calls for attention to the violent dimension of intergroup relations such as, for example, the one that expresses itself in racist discrimination. The conceptual and empirical advances described in this book search to show how this violent dimension of intergroup relations can be better understood through the articulation between psychological and social factors.

Second, this book conveys another message: The proposal that the socio-developmental dimension of psychosocial processes is fundamental for the understanding of interpersonal and intergroup relations and that the study of this dimension should be stimulated. In fact, social psychology lives predominantly in a paradigm that is principally synchronic, forgetting diachronies on various scales, among them of psychogenetic and sociogenic order. What various studies including the ones in this book propose is that intergroup relations should also be studied from a socio-developmental perspective emphasizing learning processes in their cognitive and emotional dimensions.

These two types of contributions offered by the authors of this book to the study of intergroup relations-attention to the violent dimension of this kind of social relations and the necessity of a socio-developmental approach - are largely inspired by the works of Maria Benedicta Monteiro to whom this book is dedicated.

The oeuvre of Maria has always been inspired by the insight that social inequalities and discrimination can be easily overcome if we understand better the articulation between the underlying psychological and social factors and take account of the social developmental approach. In this vein, Maria was especially concerned with the articulation between social status, social norms, socio-cognitive and socialization processes in order to understand discrimination, social inequality, and intergroup conflict and violence.

The first wave of studies that Maria developed was about the learning of violence by children. It was in that context that she studied the consequences of filmed violence-spread through television-on children's aggressive responses and on the construction of a paranoid representation of the world (cf. Chap. 8 of this book)

Inspired by Jacques-Philippe Leyens, the studies that she conducted in this field constituted her Ph.D. thesis. Those studies showed not only how these violent images from TV have an impact on the learning, expression and legitimation of aggressive responses but also how these same images contribute to the construction of a fearful world and of a conformist vision of that same world. In this latter case her experimental studies with children remain unique in the literature about the paranoid construction of the world, a research line started by George Gerbner.
After Ph.D., Maria dedicated herself to the study of intergroup conflict. This was the next logical step, a logical enlargement of her initial studies about violence. the next logical step, a logical enlargement of her initial studies about violence. Using Tajfel's Social Identity Theory as a reference, three aspects characterized this research line of Maria: (a) the concern with relevant social contexts (cf. Chap. 4 of this book), (b) the asymmetries between groups and the consequences of such this book), (b) the asymmetries between groups and the consequences of such asymmetries in the reactions to conflict and (c) a question that remains obscure: the role of the history of conflicts in the way groups cope with aversive relations. Can there be a present without a past, without a historical memory? The problem there be a present without a diachronic perspective.

At the same time she studied the conflictual relations between groups in diversified organizational contexts, Maria initiated a research line on the collective diversified organizational contexts, "child a strongest axis of her work that, beginning during the nineties, focused on the comprehension of the learning and beginning during the nineties, focused on the comprehension of the children (cf. Chaps. 2 and 9 of this book).

These two lines of research - construction and reduction of prejudice-were developed in parallel. In the case of the studies about prejudice reduction, Maria's research explored, in a systematic way, hypotheses derived from the models of decategorization, mutual differentiation, common ingroup identity and dual identity (cf. Chap 5 of this book). Underlying these models are the contact hypothesis, (ci. Che theoretical core, common to all these models and theories, is the process of categorization. Based on Gordon Allort prostic and meta-analytic factor proposing social status and stecifically inter-

that is fundamental in the understanding of social
group conflicts (cf. Chaps. 1 and 3 of this book).

As mentioned, a second important contribution of Maria's research lines was her studies about the learning of prejudice and discrimination. Maria and her team studied, in an original way, the articulation between cognitive processes and norore mative constraints in relaic the children's age is important, not because prejudice decreases with age due to cognitive factors, but because when children get older, they are better in managing 列 their expressions of prejudice according to pernissive signs that present in specific contexts. That is, older children are more capable of managing the use of anti-prejudice norms according to the context and the need for a positive self-presentation (cf. Chaps. 6 and 10 of this book).

We can now wonder about what unifies such a diversified work. We suggest two meta-concerns. The first is about the need to build a social psychology of development (or a developmental social psychology) or a psycho-sociological systematic approach to the process of psychological development. This concern marked the research of Maria on the learning of violence and prejudice and on prejudice reduction.

The second unifying concern or foundational stone in Maria's research is the idea that status inequality is a key variable to the understanding of 
psycho-sociological processes. This key variable has helped understand the origins and consequences of conflicts ever since the studies that she developed about intergroup relations and intergroup conflict in organizational contexts. This concern was also present in the studies of Maria about the conflicts associated with ethnic categorizations. In their researches the fact that low-status groups discriminate less than high-status groups is a pervasive result. Also, in Maria's studies about the learning and reduction of prejudice, a very early internalization of a dominated position emerged. Of course, in many circumstances, minorities internalize the ideologies of domination, and the costs of revolting for social change are much higher for them than for those who are simply committed to maintaining the status quo. But the history of the world is also the history of minorities' revolts and victories.

Inspired by these key contributions of Maria's work, each of the chapters of this book addresses one or even both of these meta-concerns from a particular angle. The book is organized in three parts. The chapters in the first part entitled Power, Self and Intergroup Relations introduce some of the most fundamental concepts, ideas and findings on the consequences of and responses to people's position in asymmetric social relations and reflect on how they are intertwined with people's self-expression and self-development from early on. In Chap. 1 Ana Guinote and Alice Cai present a comprehensive, scholarly review on the effects of power on powerholders. Power is with no doubts a key concept if one wants to understand asymmetric social relations. The chapter does not only bring together the most important approaches to the understanding of what it means to be in a powerful position, but also proposes a very clear conclusion namely that power amplifies the active self of the powerholder, a self that is understood as situated and linked to the social context. Implications of this conclusion resonate perfectly with the skeptical yet optimistic spirit of Maria's work and of this book: Yes, power may magnify problematic self-aspects such as tendencies to preserve one's power and to pay less attention to other's needs compared to one's own - tendencies that contribute to the maintenance and aggravation of social inequality beyond of what is acceptable. Yet what is magnified by power depends on what dominates in the person and in the contextualized situation, including the possible inclusion of others in the self and the possible endorsement of ideologies promoting equality. Chapter 2 by Dalila França then introduces the socio-developmental perspective in a didactic overview on the socio-cognitive self-development of children. It equips the reader with fundamental background knowledge that is useful for the understanding of later chapters reporting research results with children of different age. What this overview makes clear, among others, is how closely children's self is intertwined from the beginning with the social world they live in, how fundamental the role of social categorization is for children's understanding of the social world and themselves as part of it, how the notion of their position in social structure becomes more and more sophisticated over the course of their self-development, and how much children advance with age in the flexible mastering of complex, often contradicting social affordances within interpersonal, intergroup and institutional contexts. Chapter 3 by Joana Alexandre, Miriam Rosa and Sven Waldzus addresses how asymmetric status positions work out in intergroup relations. In particular, the chapter focuses on one of the possible ways in which disadvantaged groups can deal with their situation: Social creativity. This chapter introduces social identity theory, which is fundamental for the understanding of asymmetric intergroup relations and has played a key role in Maria Benedicta Monteiro's thinking and work. Much in line with Tajfel's thinking, in a study on children from different ethnic backgrounds the authors present evidence how under circumstances social creativity can contribute to the upholding of the status quo. However, the authors also present empirical results from several studies in which they demonstrate how minorities are able to hold views on social reality, particularly on more inclusive superordinate categories, that are specifically, and very systematically distinct from the views held by their dominant majority outgroups. With that they provide evidence for the so far neglected emancipative potential of social creativity in studies with members of ethnic minorities in Portugal, members of a strong belief minority (Evangelic Protestants in Portugal) and one study with people from Porto- the allegedly minor rival of Lisbon. They claim that-compared to the alternative strategy of open social competition with the powerful outgroup - social creativity has been underestimated as a strategy of social change.

The second part entitled Social Construction of Identities and Social Categories contains three relatively specialized chapters that focus on the advancement of existing knowledge by proposing new (or renewed) theoretical positions. All three chapters have in common that they highlight the socially constructed nature of social identities and meaningful social categories, and that how these identities and categories are constructed has an impact on the relations between members of these categories. They also have in common the underlying motive to elaborate on ways of prejudice reduction and their obstacles. In Chap. 4, Jacques-Philippe Leyens and Jorge Vala guide our attention to the importance of the ideological dimension of intergroup relations. This dimension had been emphasized already by Tajfel in his latest writings but has then been largely neglected in intergroup research. This chapter covers research on explicit ideologies such as colorblindness and multiculturalism as well as equalitarianism and meritocracy, but also on rather ideology constituting fundamental beliefs such as belief in a just world, limited scope of justice and denial of full humanity to outgroup members. The research the authors report demonstrates how ideologies and shared fundamental beliefs have a pervasive influence on people's construction of reality and can bias their judgment and their moral feelings, often undetected by their consciousness. Importantly, these processes are fundamental for the legitimization of asymmetric status and power relations between members of different social groups. Chapter 5 by Sam Gaertner, Rita Guerra, Margarida Rebelo, John Dovidio, Erick Hehman and Mathew Deegan proposes a new, functional approach to the understanding of how effectively prejudice can be reduced in members of majorities and minorities by either recategorizing completely as members of a more inclusive common ingroup or by creating a dual identity, that is simultaneous salience of common ingroup identity and subgroup identity. The efficacy of these two forms of recategorization for prejudice reduction had been found to differ depending on 
whether group members are in a minority or in a majority group. Contradicting results on this efficacy in the US and in Portugal required and inspired the development of the functional approach that is presented in this chapter. It emphasizes the importance of taking into account the larger social context when considering the groups' interests as causing and motivating group members' attitudes as these interests are not generic for majorities or minorities as such. In Chap. 6, Annelyse Pereira reflects on the role of social norms on the one hand and social beliefs on the other hand in regulating expressions of prejudice. After introducing these concepts in brief but informative reviews, the author uses the example of attitudes towards homosexuals as a vehicle to elaborate the complex interaction between these two fundamental factors. In times of social change, social norms on how to think about particular intergroup relations might change faster than beliefs about the nature of social groups or vice versa, which can produce contradictory or paradoxical effects on people's expressions and enactment of prejudice. This is another example of a recurrent theme in the work of Maria Benedicta Monteiro and those that were trained or inspired by her: The individual's adaptive maneuvering within complex psychosocial constellations explains their more or less prejudiced responses better than single (e.g., cognitive) factor or single (positive distinctiveness) motive approaches.

The last part Social Developmental Processes of Violence elaborates the conditions and genesis of violence in developmental processes more directly, but each chapter focusing on a very distinct aspect. In Chap. 7 by Maria Manuela Calheiros and Leonor Rodrigues the violence lies in the maltreatment of children, and the chapter is focused on one key factor of this phenomenon: Caregivers' cognition in parent-child interactions. After reviewing literature on different sources of variability in these cognitions that have been proposed as well as on the importance of caregiver cognition for the explanation of maltreatment, the chapter presents original research with a sample of abusive mothers. This study tests how much previous experiences with the child in focus and other children, as well as current perceptions of the child may influence abusive mothers' values, beliefs and situational attributions. With some exceptions, results seem to indicate that previous experience is much less important than current perceptions of the child, and if there is any impact of previous experience it is there rather because it shapes current perception as well. In their own way these results underline the value that a social psychological approach has for the understanding of child maltreatment. Chapter 8 by Patricia Arriaga, Dolf Zillmann and Francisco Esteves is a comprehensive state of the art review on the effects that exposure to or enactment of violence in mainstream media has on aggressive behavior, emotions and empathy. In line with contemporary technological developments the authors also cover the more and more widespread consumption of violent video games, which put the player in a more active role than traditional media (such as television) put their viewers. As the field is extremely controversial, the authors are very careful and rigorous in their analysis of the actually existing evidence as well as in their conclusions and recommendations for future research. Despite all controversy, and after reviewing existing literature as well as a large number of own empirical work the authors come to the conclusion that there is an impressive amount of evidence for increased aggressive motivation and impulsivity as a result of exposure to media violence, but that it is not clear yet how much it affects people's real-life behavior. Nevertheless, it is clear that there is no evidence for cathartic effects, a topic also explored by it is clear Benedicta Monteiro in her research on the effects of filmed violence and an idea that had been present in the controversy for decades but can now be abandoned. In Chap. 9 João António, Rita Correia, Allard Feddes and Rita Morais give a doned. In Chap. 9 João Antonio, Rita Correia, Allard Fedele relations develop in childhood. There review touches several important aspects such as acculturation goals of minorities and their meta-perceptions of the majorities' acculturation preferences, the importance of social comparisons as well as the way how the broader social context, particularly more inclusive superordinate categories, is related to status asymmetries between children from different ethnic background. Again, like in previous chapters, the importance to take into account social context factors in the understanding of intergroup relations is one of the most important take-home messages from this chapter. For instance, effects of as well as preferences for meculturation strategies such as assimilation or integration depend on minorities' perceptions of what the majority expects them to be or do. And again, like in Chap. 5 , it was the challenge to deal with results of research conducted in Portugal that contradicted previous findings in Anglo-Saxon countries that inspired and required the advancement in theorizing towards more contextual models. Finally, Chap. 10 by Ricardo Rodrigues, Adam Rutland and Elizabeth Collins presents a new complete theoretical model of children's intergroup attitudes. It builds on three previous models that had been proposed to explain the dynamic variation of prejudiced responses during child development and empirically backed up in the literature, but it has the intention to combine the major ideas of all three of these previous approaches in one comprehensive and integrative model. In the center of this theoretical models are two strong social norms, the ingroup loyalty norm and the norm not to be prejudiced (outgroup fairness norm), but the model takes a social developmental and social psychological stand simultaneously. Therefore it has two developmental and social pe regarding longer lasting changes in the availability and interiorization of these two norms and one regarding the situational and context dependent salience of these norms. With this combination the authors are able not only to explain existing results but also to generate new systematic hypotheses, still to be tested, for a variety of social contexts modeled by socio-structural variables proposed by social identity theory, such as status differences, their stability and legitimacy.

One of the major characteristics of this book is that it is rich and full of innovative ideas. Many chapters contain scholarly reviews, present new data or articulate new and innovative theoretical positions. Another characteristic is related to the first, namely the great variety and heterogeneity of the different research lines presented in the different chapters. Clearly these different research lines all go into different directions, rendering a concluding and integrating final chapter obsolete. Nevertheless, apart from all being inspired by Maria Benedicta Monteiro's research interests and works, these chapters share more common ground and more common 
concerns than one might think after going into the details. The way how social reality is constructed as a hierarchical order, how social norms and beliefs on how to uphold or challenge this social order are learned, the way how shared ideas are learned and repeatedly processed in these complex constructions - all of it is necessary to be taken into account if one intends to understand how violent social relations develop, perpetuate themselves and can be changed.

As editors of this volume, we would like to thank all the colleagues that contributed with their enthusiasm and intellectual commitment to make this book in honor of Maria Benedicta Monteiro possible. Their contributions come from different universities across Europe, the United States and Brazil and are representative of an important part of the intellectual network of Maria. We also would like to thank all reviewers of the papers included in this book. Their generous help definitively contributed to improve the quality of this work. A special thank you goes to Dr. Leonor Rodrigues who helped the editors in all phases of the organization of this volume. The preparation of this book would not have been possible without her generosity, support and substantive suggestions. As editors, we are also grateful to the Centro de Investigação e Intervenção Social, funded by Fundação para a Ciência e a Tecnologia (National Science Foundation), and the School of Social Sciences, University Institute of Lisbon (ISCTE-IUL) for the financial support that allowed the publication of this book. It is our sincere hope that this book will inspire new synergies between the study of intergroup relations, the analysis of social and interpersonal violence and a socio-developmental approach of the socio-psychological phenomena.

Jorge Vala Sven Waldzus Maria Manuela Calheiros 